Benchmark

\title{
Concurrent Isolation of Ribosomal, Messenger, and Low Molecular Weight RNA
}

BioTechniques 33:1122-1124 (November 2002)

\section{Christine M. Stellrecht and Varsha Gandhi \\ University of Texas \\ M.D. Anderson Cancer Center, Houston, TX, USA}

The analysis of the cellular and molecular metabolism of anticancer drugs has provided important information for optimizing the design of clinical trials (9). In recent years, there has been an increasing use and development of RNAdirected chemotherapeutic agents, such as ribonucleotide analogs $(3,5,11,13)$, actinomycin D (14), and flavopiridol (7). To understand their mechanisms of action, it is essential to analyze each of the various RNA species because the compound may be differentially incorporated and/or exert a dissimilar activity on the three RNA polymerases (8). Such an analysis can be achieved through the examination of the three main classes of RNA (rRNA, mRNA, and low molecular weight RNA, sRNA, which includes $5 \mathrm{~S}$ and tRNA). Historically, this type of analysis was performed either by using an in vitro system in which the three RNA polymerases were isolated and assayed separately (8) or by isolating and crudely fractionating total RNA through a sucrose gradient (15). There are numerous techniques and kits available for the isolation and separation of mRNA $(1,6,10)$, but they do not allow for the concurrent separation of rRNA and sRNA. The three RNA species can be separated and isolated using high-pressure liquid chromatography (2), but the costs of the instruments and columns are beyond the reach of most researchers.

The in vivo and ex vivo effects of
RNA-directed compounds on each of the three RNA species can be characterized by using a simultaneous separation method. Here we describe a method for RNA isolation that allows for the simultaneous separation and enrichment of mRNA, rRNA, and sRNA. This procedure utilizes standard oligo(dT) chromatography for mRNA isolation while the sRNA and rRNA are isolated by subjecting the non-polyadenylated RNA to anion-exchange chromatography. This was accomplished by combining and modifying three strategies for isolating various RNA forms (Figure 1). Specifically, $1 \times$ $10^{8}$ cells from the multiple myeloma cell line, MM.1S (4), were pelleted by centrifugation. The pellets were either used directly or flash-frozen on dry ice and stored at $-80^{\circ} \mathrm{C}$. The fresh or flashfrozen cell pellets were lysed in $15 \mathrm{~mL}$ FastTrack $^{\mathrm{TM}} 2.0$ lysis buffer $(200 \mathrm{mM}$ $\mathrm{NaCl}, 200 \mathrm{mM}$ Tris, pH 7.5, $1.5 \mathrm{mM}$ $\mathrm{MgCl}_{2}, 2 \%$ SDS; proprietary mixture of proteases) and digested per the manufacturer's instructions (Invitrogen, Carsbad, CA, USA). This cell lysate was used to separate the three RNA species (Figure 1, no. 1).

The lysate was first applied to $75 \mathrm{mg}$ oligo(dT) cellulose (FastTrack 2.0) to separate and enrich the mRNA per the manufacturer's protocol, with the following modifications (Figure 1, no. 2). The oligo(dT) cellulose was pelleted at room temperature by centrifugation for $5 \mathrm{~min}$ at $5000 \times \mathrm{g}$. The supernatant was removed and saved on ice for further isolation of rRNA and sRNA. To wash the mRNA-bound cellulose, the pellet was resuspended in $20 \mathrm{~mL}$ Binding Buffer (500 mM NaCl, 10 mM Tris-Cl, $\mathrm{pH} 7.5)$ and centrifuged as before. The
20-mL wash supernatant was combined and saved with the $15-\mathrm{mL}$ binding supernatant. The pellet was again washed with $10 \mathrm{~mL}$ Binding Buffer, but the supernatant from this wash was discarded. To remove nonspecifically bound RNA, the pellets were washed approximately five times in $10 \mathrm{~mL}$ Low Salt Wash Buffer $(250 \mathrm{mM} \mathrm{NaCl}, 10 \mathrm{mM}$ Tris- $\mathrm{Cl}, \mathrm{pH}$ 7.5) and centrifuged as before. The $10-\mathrm{mL}$ supernatant from the first Low Salt Wash was combined and saved with the previously saved supernatant. The remainder of the mRNA isolation was performed according to the manufacturer's protocol (Figure 1, no. 3$)$. The mRNA $(10-30 \mu \mathrm{g})$ was resuspended in $20 \mu \mathrm{L}$ DEPC-treated water.

The supernatants that had been saved from the mRNA isolation, approximately $45 \mathrm{~mL}$, were precipitated with equal volume of isopropanol at $-20^{\circ} \mathrm{C}$ overnight and centrifuged at $12000 \times g$ for $30 \mathrm{~min}$ at $4{ }^{\circ} \mathrm{C}$ in a Sorval ss-34 rotor. The supernatant was discarded, and the pellets were washed with $70 \%$ ethanol (Figure 1, no. 4). This pelleted material contained rRNA, sRNA, genomic DNA, proteins, and other cellular materials. The pellet was allowed to air dry briefly, and the RNA was isolated from this mixture by extraction with $10 \mathrm{~mL}$ RNAzol B (Teltest, Friendswood, TX, USA) per the manufacturer's instructions, with all centrifugations performed at $12000 \times g$ for $15 \mathrm{~min}$ at $4^{\circ} \mathrm{C}$ in a Sorval ss-34 rotor (Figure 1, no. 5). This extraction allows for the removal of the DNA, protein, and other cellular contaminates. In addition, incorporating this step permits the quantitation of the RNA before applying it to the anion exchange resin. This helps to maximize the amount of 
RNA binding and isolation while avoiding problems caused by exceeding the binding capacity of the anion exchange resin. The resulting rRNA and sRNA material (0.5-1 mg) was resuspended in approximately $500 \mu \mathrm{L}$ DEPC-treated water, and the concentration was determined spectrophotometrically.

The sRNA was separated from the rRNA by anion exchange chromatography using a RNA/DNA Midi kit (Qiagen,Valencia, CA, USA). The sRNA isolation procedure was modified from the Qiagen anion-exchange protocol to improve the yield of sRNA. Two hundred micrograms of RNA (containing rRNA and sRNA) were mixed with 1 mL Buffer QRL1 and then diluted with $9 \mathrm{~mL}$ Buffer QRV2, vortex-mixed, and applied to a pre-equilibrated resin tip (Figure 1, no. 6). The sRNA was eluted with $6 \mathrm{~mL}$ Buffer QRW2 (50 mM MOPS, pH 7.0, $750 \mathrm{mM} \mathrm{NaCl}, 15 \%$

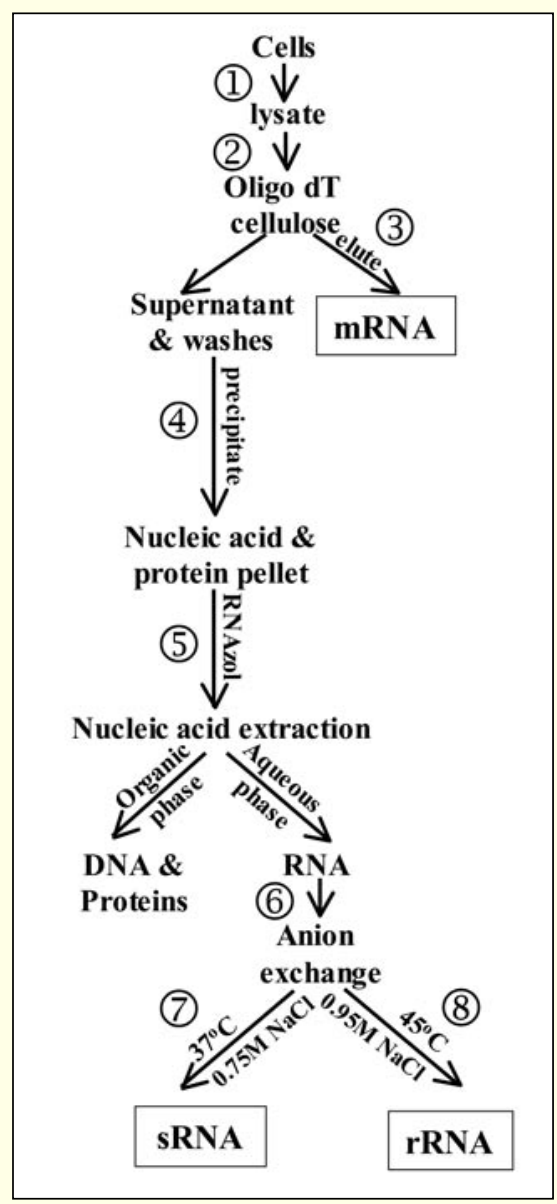

Figure 1. Schematic outline of isolation procedure. Numbers in circles represent steps described in the text. ethanol) preheated to $37^{\circ} \mathrm{C}$ (Figure 1 , no. 7). We have found that preheating the QRW2 sRNA elution buffer to $37^{\circ} \mathrm{C}$ before adding it to the resin increased the sRNA yield. Therefore, all of our sRNA elutions were performed at $37^{\circ} \mathrm{C}$ rather than room temperature as suggested by the manufacturer. However, care was taken not to increase the temperature higher than $37^{\circ} \mathrm{C}$ because at $45^{\circ} \mathrm{C}$, rRNA also eluted with the sRNA. For further enhancement of sRNA recovery, a carrier, $22 \mu \mathrm{L}(20 \mu \mathrm{g} / \mu \mathrm{L})$ glycogen (Roche Applied Science, Indianapolis, IN, USA) were added before precipitation with $6 \mathrm{~mL}$ isopropanol. The remainder of the sRNA and rRNA isolation followed the manufacturer's instructions (Figure 1, no. 8). The sRNA (10-30 $\mu \mathrm{g})$ and rRNA (150-170 $\mu \mathrm{g})$ were resuspended in 30 and $100 \mu \mathrm{L}$ DEPC-treated water, respectively.

This procedure may be further streamlined by isopropanol precipitating a fraction of the non-oligo(dT)bound material and directly resuspending the pellet in QRL1 buffer for application to the anion exchange column, thus eliminating the RNAzol B

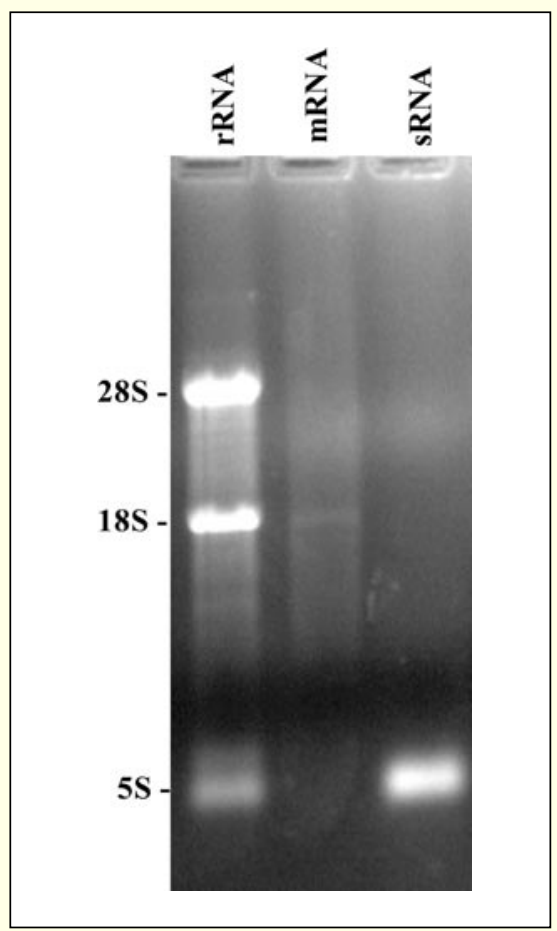

Figure 2. Enrichment of rRNA, mRNA, and sRNA. The rRNA (4-5 $\mu \mathrm{g})$, mRNA $(1-2 \mu \mathrm{g})$, and sRNA $(1-2 \mu \mathrm{g})$ were denatured, combined with ethidium bromide $(0.5 \mu \mathrm{g})$, and electrophoresed on a $4 \%$ formaldehyde, $1 \%$ agarose gel. 
extraction. The major caveat to this is the competition for column binding by other cellular materials present in this fraction (i.e., DNA); therefore, less RNA will be recovered. In addition, the amount of the material to be precipitated and applied to the column will need to be optimized to prevent column overloading. For our purposes, we needed to maximize the amount of RNA recovered for further manipulation and analysis of the RNA species.

The quality of the RNA species enrichment was assessed after the samples had been electrophoresed on a $4 \%$ formaldehyde gel $/ 1 \%$ agarose gel (Figure 2), prepared as previously described (12). The ethidium bromide staining intensity was visualized, and the RNA species enrichment was quantitatively assessed using 1D Image Analysis software (Eastman Kodak, Rochester, NY, USA). As expected, the results show a high level of enrichment of the mRNA. After adjusting for the micrograms of RNA per lane, the intensity of the $28 \mathrm{~S}$ band was on average greater than 20 -fold higher in the rRNA samples than in the mRNA samples. The sRNA appeared visually pure and was found to have on average a 200fold higher intensity of the sRNA band, as compared to the $18 \mathrm{~S}$ band in the same sample. A comparison of the $18 \mathrm{~S}$ intensity per $\mathrm{cm}^{2}$ to the mRNA intensity per $\mathrm{cm}^{2}$ in the rRNA samples averaged 150-fold higher for the $18 \mathrm{~S}$, while in the mRNA samples this ratio was on average 6.5 -fold higher. Thus, although some of the other RNA species remained in the rRNA sample, the vast majority of the RNA in this fraction was rRNA.

In summary, these results show that, in addition to a high level of mRNA enrichment, this procedure yields sRNA and rRNA with a high degree of enrichment. Using RNA isolated by this technique, we have made several assessments of the differential effects of ribonucleoside analogs on the three RNA populations, including drug incorporation into RNA, rate of RNA incorporation, and drug effects on RNA synthesis rate $(3,11)$. Thus, the development of this protocol readily permits the in vivo and ex vivo analysis on the three RNA polymerases and their respective RNA product.

\section{ACKNOWLEDGMENTS}

MM.1S cells were obtained from the laboratory of Drs. Nancy Krett and Steven Rosen, Robert H. Lurie Comprehensive Cancer Center, Northwestern University, Chicago. This work was supported in part by grant no. CA85915 from the National Cancer Institute, Department of Health and Human Services; a Translational Research Award from the Leukemia Society of America. This work was also supported by the Rapid Access to Intervention Development program, Developmental Therapeutics, National Cancer Institute.

\section{REFERENCES}

1.Aviv, H. and P. Leder. 1972. Purification of biologically active globin messenger RNA by chromatography on oligothymidylic acid-cellulose. Proc. Natl. Acad. Sci. USA 69:14081412.

2.Azarani, A. and K.H. Hecker. 2001. RNA analysis by ion-pair reversed-phase high performance liquid chromatography. Nucleic Acids Res. 29:E7.

3.Gandhi, V., M. Ayres, R.G. Halgren, N.L. Krett, R.A. Newman, and S.T. Rosen. 2001. 8-chloro-cAMP and 8-chloro-adenosine act by the same mechanism in multiple myeloma cells. Cancer Res. 61:5474-5479.

4.Goldman-Leikin, R.E., H.R. Salwen, C.V. Herst, D. Variakojis, M.L. Bian, M.M. Le Beau, P. Selvanayagan, R. Marder, et al. 1989. Characterization of a novel myeloma cell line, MM.1. J. L. Clin. Med. 113:335-345.

5.Huang, P., A. Sandoval, E. Van Den Neste, M.J. Keating, and W. Plunkett. 2000. Inhibition of RNA transcription: a biochemical mechanism of action against chronic lymphocytic leukemia cells by fludarabine. Leukemia 14:1405-1413.

6.Jacobson, A. 1987. Purification and fractionation of poly(A)+ RNA. Methods Enzymol. 152:254-261.

7.Lam, L.T., O.K. Pickeral, A.C. Peng, A. Rosenwald, E.M. Hurt, J.M. Giltnane, L.M. Averett, H. Zhao, et al. 2001. Genomic-scale measurement of mRNA turnover and the mechanisms of action of the anti-cancer drug flavopiridol. Genome Biol. 2: research0041.1-research0041.11.

8.Lindell, T.J., F. Weinberg, P.W. Morris, R.G. Roeder, and W.R. Rutter. 1970. Specific Inhibition of nuclear RNA polymerase II by $\alpha$-Amanitin. Science 170:447-449.

9.Plunkett, W. and V. Gandhi. 1996. Pharmacology of purine nucleoside analogues. Hematol. Cell Ther. 38 (Suppl 2):S67-74.

10.Stellrecht, C.M., G. Fraizer, C. Selvanayagam, L.Y. Chao, A. Lee, and G.F. Saunders. 1993. Transcriptional regulation of a hematopoietic proteoglycan core protein gene during hematopoiesis. J. Biol. Chem. 268:4078-4084.
11.Stellrecht, C.M., N. Krett, M. Ayres, S. Rosen, and V. Gandhi. 2001. 8-chloro-cAMP serves as a prodrug for the RNA directed nucleoside analog, 8-chloro-adenosine. In Acute Leukemia IX, Springer-Verlag, Berlin.

12.Stellrecht, C.M., W.M. Mars, H. Miwa, M. Beran, and G.F. Saunders. 1991. Expression pattern of a hematopoietic proteoglycan core protein gene during human hematopoiesis. Differentiation 48:127-135.

13.Tabata, S., M. Tanaka, Y. Endo, T. Obata, A. Matsuda, and T. Sasaki. 1997. Anti-tumor mechanisms of 3 '-ethynyluridine and $3^{\prime}$ ethynylcytidine as RNA synthesis inhibitors: development and characterization of $3^{\prime}$ ethynyluridine-resistant cells. Cancer Lett. 116:225-231.

14.Tournade, M.F., C. Com-Nougue, J. de Kraker, R. Ludwig, A. Rey, J.M. Burgers, B. Sandstedt, J. Godzinski, et al. 2001. Optimal duration of preoperative therapy in unilateral and nonmetastatic Wilms' tumor in children older than 6 months: results of the Ninth International Society of Pediatric Oncology Wilms' Tumor Trial and Study. J. Clin. Oncol. 19:488-500.

15.Wells, D.J., L.S. Stoddard, M.J. Getz, and H.L. Moses. 1979. $\alpha$-amanitin and 5-fluorouridine inhibition of serum-stimulated DNA synthesis in quiescent AKR-2B mouse embryo cells. J. Cell Physiol. 100:199-214.

Received 10 June 2002; accepted 29 July 2002.

\author{
Address correspondence to: \\ Dr. Varsha Gandhi \\ Department of Experimental Therapeutics \\ Box 71, University of Texas M.D. Anderson \\ Cancer Center \\ 1515 Holcombe Blvd. \\ Houston, TX 77030, USA \\ e-mail:vgandhi@mdanderson.org
}

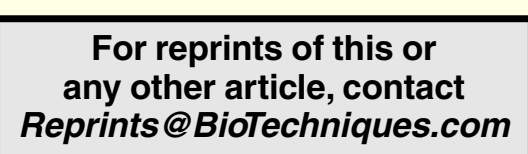

